\title{
SST Forcings and Sahel Rainfall Variability in Simulations of the Twentieth and Twenty-First Centuries
}

\author{
M. BIASUTTI \\ Lamont-Doherty Earth Observatory, Columbia University, Palisades, New York \\ I. M. HELD \\ NOAA/Geophysical Fluid Dynamics Laboratory, Princeton, New Jersey \\ A. H. SOBEL \\ Columbia University, Palisades, New York \\ A. GIANNINI \\ International Research Institute for Climate and Society, Palisades, New York
}

(Manuscript received 13 February 2007, in final form 26 September 2007)

\begin{abstract}
The outlook for Sahel precipitation in coupled simulations of the twenty-first century is very uncertain, with different models disagreeing even on the sign of the trends. Such disagreement is especially surprising in light of the robust response of the same coupled models to the twentieth-century forcings.

This study presents a statistical analysis of the preindustrial, twentieth-century and twenty-first-century A1B scenario simulations in the latest Coupled Model Intercomparison Project 3 (CMIP3) dataset; it shows that the relationship that links Sahel rainfall anomalies to tropical sea surface temperature (SST) anomalies at interannual time scales in observations is reproduced by most models, independently of the change in the basic state as the world warms.

The same SST-Sahel relationship can be used to predict the simulated twentieth-century changes in Sahel rainfall from each model's simulation of changes in Indo-Pacific SST and Atlantic SST meridional gradient, although the prediction overestimates the simulated trends. Conversely, such a relationship does not explain the rainfall trend in the twenty-first century in a majority of models. These results are consistent with there being, in most models, a substantial direct positive effect of atmospheric greenhouse gases on Sahel rainfall, not mediated through SST.
\end{abstract}

\section{Introduction}

During the second half of the twentieth century, Africa witnessed one of the most remarkable climate signals of the recent observational record in the pronounced negative trend in rainfall in the semiarid Sahel (i.e., the southern edge of the Sahara desert), which culminated in the devastating drought of 1984 (e.g., Nicholson 1980; Nicholson et al. 2000).

Given the large environmental and human impact of drought in this region, it is important to understand whether the drought of the 1970s and 1980s was a con-

Corresponding author address: Michela Biasutti, LamontDoherty Earth Observatory of Columbia University, 61 Route 9W, P.O. Box 1000, Palisades, NY 10968-8000.

E-mail: biasutti@ldeo.columbia.edu sequence of global warming and a harbinger of worse things to come, as many outside the scholarly community have already suggested (e.g., Gore 2006), or whether the past drought was caused by other factors and the most recent upswing in rainfall (Nicholson et al. 2000) is the beginning of a steady recovery.

Our understanding of the Sahel drought has been growing thanks to many modeling studies that have employed both uncoupled and coupled general circulation models (GCMs). Recently, different atmospheric GCMs (Folland et al. 1986; Giannini et al. 2003; Tippett and Giannini 2006; Lu and Delworth 2005; Hoerling et al. 2006), forced with the historic time series of global sea surface temperatures (SSTs), have been able to reproduce the main outlines of the twentieth-century Sahel pluvials and droughts, thus demonstrating that oceanic forcing has been the dominant driver of rainfall 
variability in this region. It appears that land surface and vegetation processes and perhaps dust feedbacks may amplify rainfall anomalies, but they do not in themselves create realistic anomalies in the absence of these SST variations (e.g., Zeng et al. 1999; Giannini et al. 2003; Rosenfeld et al. 2001).

Other modeling studies have tackled the question of whether we should attribute the twentieth-century Sahel droughts to internal climate variability or to anthropogenic emissions of greenhouse gases and aerosols. Rotstayn and Lohmann (2002) and Hoerling et al. (2006), following Folland et al. (1986) and others, have both emphasized the role of the differential warming of the Northern and Southern Hemispheres in determining the meridional location of the Atlantic ITCZ and the reach of the West African monsoon. The former study, however, argued for the role of anthropogenic aerosol in forcing Sahel drought, and the latter argued for natural variability. Giannini et al. $(2003,2005)$ and Bader and Latif (2003) have emphasized the warming of the tropical oceans, especially the Indian Ocean, as a possible cause of the drying of the Sahel. Such warming has been linked by Stott et al. (2000) and Knutson et al. (1999), among others, to anthropogenic greenhouse gases.

Biasutti and Giannini (2006) took advantage of the Coupled Model Intercomparison Project 3 (CMIP3) dataset and looked at Sahel rainfall variations in 19 different coupled GCMs. Most models (16 out of 19) simulate a significantly drier Sahel at the end of the twentieth century with respect to the preindustrial times. At least $30 \%$ of the observed negative rainfall trend over the 1930-2000 period was estimated to be externally—and most likely anthropogenically—forced. They concluded that although the role of internal climate variability was predominant in forcing the sharp decline in Sahel rainfall in the 1960s and 1970s, anthropogenic influences have also been substantial, giving reasons to worry about the future.

In simulations in which greenhouse gases are the only or the dominant forcing, the agreement seen in the latetwentieth-century response breaks down (Held et al. 2005; Biasutti and Giannini 2006; Cook and Vizy 2006; Lau et al. 2006). The fact that the twentieth-century drying does not continue in the twenty-first century in a majority of models would suggest that aerosols, and not greenhouse gases, have forced drought on the Sahel in these models of the twentieth century.

Biasutti and Giannini (2006) attribute the crossmodel consensus in the twentieth-century integrations to the fact that models respond in a consistent fashion to the cross-equatorial gradient of SST forced by reflective aerosols, and Hoerling et al. (2006) point to the



FIG. 1. The Sahel rainfall index during the twentieth and twenty-first centuries, as simulated by the GFDL (solid line) and MIROC (dashed line) models. Anomalies are in $\mathrm{mm} \mathrm{day}^{-1}$.

reversal in the Atlantic SST gradient as the global warming signal intensifies and aerosols go away as the cause of a predicted recovery in Sahel rainfall. However, Held et al. (2005) find that the coupled models of the Geophysical Fluid Dynamics Laboratory (GFDL) respond to increasing greenhouse gases with a very robust drying in the Sahel, even in the presence of a reversal of the Atlantic gradient. Moreover, simulations with some uncoupled atmospheric models do indicate a drying of the Sahel in response to either a uniform warming or a warming of the Indian Ocean (Held et al. 2005; Bader and Latif 2003), which indicates that drying is a plausible response to increased greenhouse gas concentrations.

Our understanding of the processes governing tropical rainfall is insufficient to predict with certainty a trend of either sign. On the one hand, enhanced precipitation in the monsoons would be expected as a consequence of the enhanced land-sea temperature contrast typical of the global warming signal (Haarsma et al. 2005). On the other hand, regions where moisture availability is limited by dry advection (such as the Sahel, which lies downwind from the Sahara) might dry in the future if they do not reach the new threshold in boundary layer moist static energy necessary for deep convection in a warmer, more stable environment (Neelin et al. 2003). Thus, as pointed out by several studies (Held et al. 2005; Cook and Vizy 2006; Lau et al. 2006; Biasutti and Giannini 2006) and exemplified by Fig. 1, the outlook for rainfall in the Sahel is very uncertain: we do not know whether we should expect positive or negative rainfall anomalies in the Sahel under global warming. 
We are interested in understanding how such disparate predictions for the future of Sahel rainfall come about in different models. One possibility is that different models have different sensitivities to local and remote SST forcings of rainfall over the Sahel. For example, a warmer North Atlantic Ocean could enhance the southerly flow and hence the moisture flux into the Sahel and could lead to more rain. A warmer IndoPacific Ocean could warm and stabilize the tropical troposphere and, by analogy to a warm ENSO event, lead to a drier Sahel. If different models weigh these processes differently, their outlooks for Sahel rainfall will differ as well. Another possibility is that the models predict patterns of SST anomalies for the twenty-first century that are different enough to force different Sahel responses, even if the sensitivities in each model are quite similar. Moreover, other forcings besides SST can become more important in the future: for example, land surface temperatures are expected to rise faster than SSTs (e.g., Houghton et al. 1996; Sutton et al. 2007), leading to an enhanced land-sea contrast and, possibly, monsoon rainfall (Haarsma et al. 2005). Again, models might differ in how strong a land-sea contrast they predict or in how sensitive they are to this mechanism.

We focus on the role of changing SST in forcing changes in Sahel rainfall. We analyze the preindustrial control integrations, the twentieth-century integrations, and the twenty-first-century $\mathrm{A}_{1} \mathrm{~B}^{1}$ scenario integrations of 19 of the CMIP3 models. We estimate the sensitivity of Sahel rainfall to local and remote SST forcings by looking at the strength of the statistical relationship between the Sahel rainfall index and the relevant quantities, and we address the question of whether it is possible to predict the twenty-first-century response of a model to tropical SST changes from knowledge of its behavior in the twentieth century.

In section 2 we describe the integrations in more detail, introduce the models, and assess their overall performance in simulating Sahel rainfall variability. In section 3 we report on the statistical relationship between Sahel rainfall and SST, as simulated by the models in the preindustrial and twentieth-century integrations. In section 4 we investigate whether the relationships that have emerged at interannual time scales and in the forced changes of the twentieth century are relevant for the twenty-first-century trend, and in section 5 we offer our conclusions.

\footnotetext{
${ }^{1}$ The three A1 groups are distinguished by their technological emphasis: fossil fuel energy intensive (A1FI), non-fossil fuel energy intensive (A1T), and balanced across all energy sources (A1B).
}

\section{Datasets}

Our dataset is extracted from the CMIP3 dataset, which we obtained from the Program for Climate Model Diagnosis and Intercomparison (PCMDI) Web site. We have analyzed the twentieth-century (hereafter $\mathrm{XX}$ ), preindustrial control (hereafter PI), and A1B scenario $^{1}$ (hereafter A1B) integrations of 19 coupled models. In the XX simulations, the coupled models are forced by the historic, varying concentrations of wellmixed greenhouse gases and sulfate aerosols, and-in some models-by other anthropogenic (e.g., black carbon particulate or land-use patterns) and natural (solar output and volcanic aerosols) forcings. The PI controls have constant forcings, with $\mathrm{CO}_{2}$ and aerosol concentrations held at the preindustrial level. The A1B scenario assumes a growing world economy and technological advances, such that the concentration of $\mathrm{CO}_{2}$ reaches 700 ppmv in 2100 and stabilizes at that level, while aerosol concentration decreases. In most of our analyses we have used the entire length of the XX simulations, $200 \mathrm{yr}$ (when available) of the PI simulations, and the first $100 \mathrm{yr}$ of the A1B simulations. Table 1 provides a brief overview of the characteristics of the models and the simulations. (A full description of all models and integrations can be found at www-pcmdi. llnl.gov/ipcc/model_documentation/ipcc_model_ documentation.php and references therein.)

Our choice of models was dictated exclusively by the availability of the integrations when we recovered the data: we included all the available models, independently of the characteristics of their simulation over Africa. Although it is likely that the twenty-firstcentury simulation of Sahel rainfall can be compromised by a model's inability to reproduce the observed climatology or the observed relationship between Sahel rainfall and global SSTs for the present and recent past, we do not know a priori which model characteristics are important in determining the twenty-first-century response.

Figure 2 contrasts the annual cycle of rainfall averaged over $10^{\circ}-20^{\circ} \mathrm{N}$ across Africa both in two observational datasets [Climate Prediction Center (CPC) Merged Analysis of Precipitation (CMAP; Xie and Arkin 1996, 1997), covering 1979-99, and Hulme (Hulme 1992), covering 1900-98, which cover a drier and a wetter period, respectively] and in the models (for each model we show the climatology in the PI, XX, and A1B integrations). There is a large spread across models in the amount of precipitation falling on the Sahel, with a tendency to underestimate it, sometimes dramatically [as in the model of L'Institute Pierre-Simon Laplace (IPSL)]. All of the models at least capture the gross 
TABLE 1. Model name; resolution of the atmospheric and oceanic component models (in degrees); start date for the XX run; forcings used in the XX integrations, besides the increasing well-mixed greenhouse gases and the direct effect of sulfate aerosols (natural forcings are solar output and volcanic emissions; "land" refers to land-use changes; OC is organic carbon, BC is black carbon, IE is the indirect effect of sulfate aerosols); and length of PI run (note that for most analyses we have used 200-yr-long records, except for the high-resolution MIROC model). The letter $\mathrm{N}$ means no and Y means yes.

\begin{tabular}{|c|c|c|c|c|c|c|c|c|c|}
\hline \multirow[b]{2}{*}{ Model } & \multirow{2}{*}{$\begin{array}{l}\text { Atmospheric } \\
\text { resolution }\end{array}$} & \multirow{2}{*}{$\begin{array}{l}\text { Oceanic } \\
\text { resolution }\end{array}$} & \multirow{2}{*}{$\begin{array}{c}\text { XX } \\
\text { start } \\
\text { year }\end{array}$} & \multicolumn{5}{|c|}{$\begin{array}{l}\text { Additional } \\
\text { twentieth-century forcings }\end{array}$} & \multirow{2}{*}{$\begin{array}{l}\text { Length } \\
\text { PI }\end{array}$} \\
\hline & & & & Natural & Land & $\mathrm{OC}$ & $\mathrm{BC}$ & IE & \\
\hline $\begin{array}{l}\text { Canadian Centre for Climate Modelling and Analysis } \\
\text { Coupled GCM, version } 3\end{array}$ & $3.75 \times 3.71$ & $1.85 \times 1.85$ & 1850 & $\mathrm{~N}$ & $\mathrm{~N}$ & $\mathrm{~N}$ & $\mathrm{~N}$ & $\mathrm{~N}$ & 500 \\
\hline CNRM-CM3 & $2.81 \times 2.79$ & $2 \times 0.5$ & 1860 & $\mathrm{~N}$ & $\mathrm{~N}$ & $\mathrm{~N}$ & $\mathrm{~N}$ & $\mathrm{~N}$ & 500 \\
\hline $\begin{array}{l}\text { Commonwealth Scientific and Industrial Research } \\
\text { Organisation Mark version } 3\end{array}$ & $1.88 \times 1.87$ & $1.88 \times 0.84$ & 1871 & $\mathrm{~N}$ & $\mathrm{~N}$ & $\mathrm{~N}$ & $\mathrm{~N}$ & $\mathrm{~N}$ & 380 \\
\hline GFDL CM version 2.0 & $2.5 \times 2$ & $1 \times 1 / 3$ & 1861 & $\mathrm{Y}$ & $\mathrm{Y}$ & $\mathrm{Y}$ & $\mathrm{Y}$ & $\mathrm{N}$ & 500 \\
\hline GFDL CM version 2.1 & $2.5 \times 2$ & $1 \times 1 / 3$ & 1861 & $\mathrm{Y}$ & $\mathrm{Y}$ & $\mathrm{Y}$ & $\mathrm{Y}$ & $\mathrm{N}$ & 500 \\
\hline $\begin{array}{l}\text { Goddard Institute for Space Studies (GISS) } \\
\text { Atmosphere-Ocean model }\end{array}$ & $4 \times 3$ & $4 \times 3$ & 1850 & $\mathrm{~N}$ & $\mathrm{~N}$ & $\mathrm{~N}$ & $\mathrm{~N}$ & $\mathrm{~N}$ & 250 \\
\hline GISS Model E-H & $5 \times 4$ & $2 \times 2$ & 1880 & $\mathrm{Y}$ & $\mathrm{Y}$ & $\mathrm{Y}$ & $\mathrm{Y}$ & $\mathrm{Y}$ & 400 \\
\hline GISS Model E-R & $5 \times 4$ & $5 \times 4$ & 1880 & $\mathrm{Y}$ & $\mathrm{Y}$ & $\mathrm{Y}$ & $\mathrm{Y}$ & $\mathrm{Y}$ & 500 \\
\hline iap_fgoals1_0_g & $2.81 \times 3.05$ & $1 \times 1$ & 1850 & $\mathrm{~N}$ & $\mathrm{~N}$ & $\mathrm{~N}$ & $\mathrm{~N}$ & $\mathrm{~N}$ & 200 \\
\hline $\begin{array}{l}\text { Institute of Numerical Mathematics Coupled } \\
\text { Model, version } 3.0\end{array}$ & $5 \times 4$ & $2.5 \times 2$ & 1871 & $\mathrm{Y}$ & $\mathrm{N}$ & $\mathrm{N}$ & $\mathrm{N}$ & $\mathrm{N}$ & 330 \\
\hline IPSL Coupled Model, version 4 & $3.75 \times 2.54$ & $2 \times 1$ & 1860 & $\mathrm{~N}$ & $\mathrm{~N}$ & $\mathrm{~N}$ & $\mathrm{~N}$ & $\mathrm{~N}$ & 320 \\
\hline MIROC3.2, high-resolution version & $1.13 \times 1.12$ & $0.28 \times 0.19$ & 1900 & $\mathrm{Y}$ & $\mathrm{Y}$ & $\mathrm{Y}$ & $\mathrm{Y}$ & $\mathrm{Y}$ & 100 \\
\hline MIROC3.2, medium-resolution version & $2.81 \times 2.79$ & $1.4 \times 0.5$ & 1850 & $\mathrm{Y}$ & $\mathrm{Y}$ & $\mathrm{Y}$ & $\mathrm{Y}$ & $\mathrm{Y}$ & 500 \\
\hline MPI ECHAM5 & $1.88 \times 1.87$ & $1.5 \times 1.5$ & 1860 & $\mathrm{~N}$ & $\mathrm{~N}$ & $\mathrm{~N}$ & $\mathrm{~N}$ & $\mathrm{Y}$ & 505 \\
\hline MRI Coupled GCM version 2.3.2a & $2.81 \times 2.79$ & $2.5 \times 0.5$ & 1851 & $\mathrm{Y}$ & $\mathrm{N}$ & $\mathrm{N}$ & $\mathrm{N}$ & $\mathrm{N}$ & 350 \\
\hline NCAR CCCSM version 3.0 & $1.41 \times 1.40$ & $1.13 \times 0.27$ & 1870 & $\mathrm{Y}$ & $\mathrm{N}$ & $\mathrm{Y}$ & $\mathrm{Y}$ & $\mathrm{N}$ & 500 \\
\hline NCAR Parallel Climate Model version 1 & $2.81 \times 2.79$ & $1.13 \times 0.27$ & 1890 & $\mathrm{Y}$ & $\mathrm{N}$ & $\mathrm{N}$ & $\mathrm{N}$ & $\mathrm{N}$ & 350 \\
\hline Met Office HadCM3 & $3.75 \times 2.50$ & $1.25 \times 1.25$ & 1860 & $\mathrm{~N}$ & $\mathrm{~N}$ & $\mathrm{~N}$ & $\mathrm{~N}$ & $\mathrm{Y}$ & 341 \\
\hline $\begin{array}{l}\text { Met Office Hadley Centre Global Environmental } \\
\text { Model version } 1\end{array}$ & $1.88 \times 1.25$ & $1 \times 1 / 3$ & 1860 & $\mathrm{~N}$ & $\mathrm{~N}$ & $\mathrm{Y}$ & $\mathrm{Y}$ & $\mathrm{Y}$ & 230 \\
\hline
\end{tabular}

features of the mean seasonal cycle of Sahel rainfall, with maximum precipitation in the summer months, although some tend to simulate a faster increase of precipitation in the spring [e.g., the third climate configuration of the Met Office Unified Model (HadCM3)] and others show a slower decline in the fall [e.g., the Centre National de Recherches Météorologiques Coupled Global Climate Model, version 3 (CNRMCM3)]. The shape of the seasonal cycle is not appreciably or consistently changed across the PI, XX, and A1B simulations, and thus results in the rest of the paper are only shown for the northern monsoon season, defined as July-September (JAS).

In Fig. 3 we explore the spatial characteristics of rainfall in the region. The contour lines show the mean position of summer rainfall over Africa and the Atlantic basin in observations and the coupled models. In observations (CMAP, Fig. 3xx), the maximum JAS precipitation extends over Africa from the equator to about $18^{\circ} \mathrm{N}$ and is concentrated over the ocean in the Atlantic ITCZ, stretching from West Africa across the basin at about $8^{\circ} \mathrm{N}$. Precipitation is more intense in the ITCZ than over the continent. The models show some fairly common biases. Over Africa, in many models, rain does not extend far enough north; over the ocean, the ITCZ is often positioned too far south and widens over the Gulf of Guinea. This bias is linked to most models' inability to develop a cold tongue in the Gulf of Guinea (see Davey et al. 2002).

Given that the climatologies in these models are far from perfect (in particular, often the rainband stays shy of the Sahel), a single index defined on the basis of observations might not be optimal to capture the variability in this region. We have elected not to correct for individual model bias, and we define the Sahel index as the JAS rainfall in the $10^{\circ}-20^{\circ} \mathrm{N}$ zonal band over Africa. To provide a measure of how well the pattern of Sahel rainfall variability is captured by this index, we calculate its correlation with global rainfall in each PI integration (Fig. 3, shading). In observations (Fig. 3xx), correlations are, as expected, strong and positive in the region used to define the Sahel index, but they are quite noisy elsewhere (this might in part be due to the shortness of the CMAP record). There is a signature of the dipole between the Sahel and the Gulf of Guinea and some positive correlation 

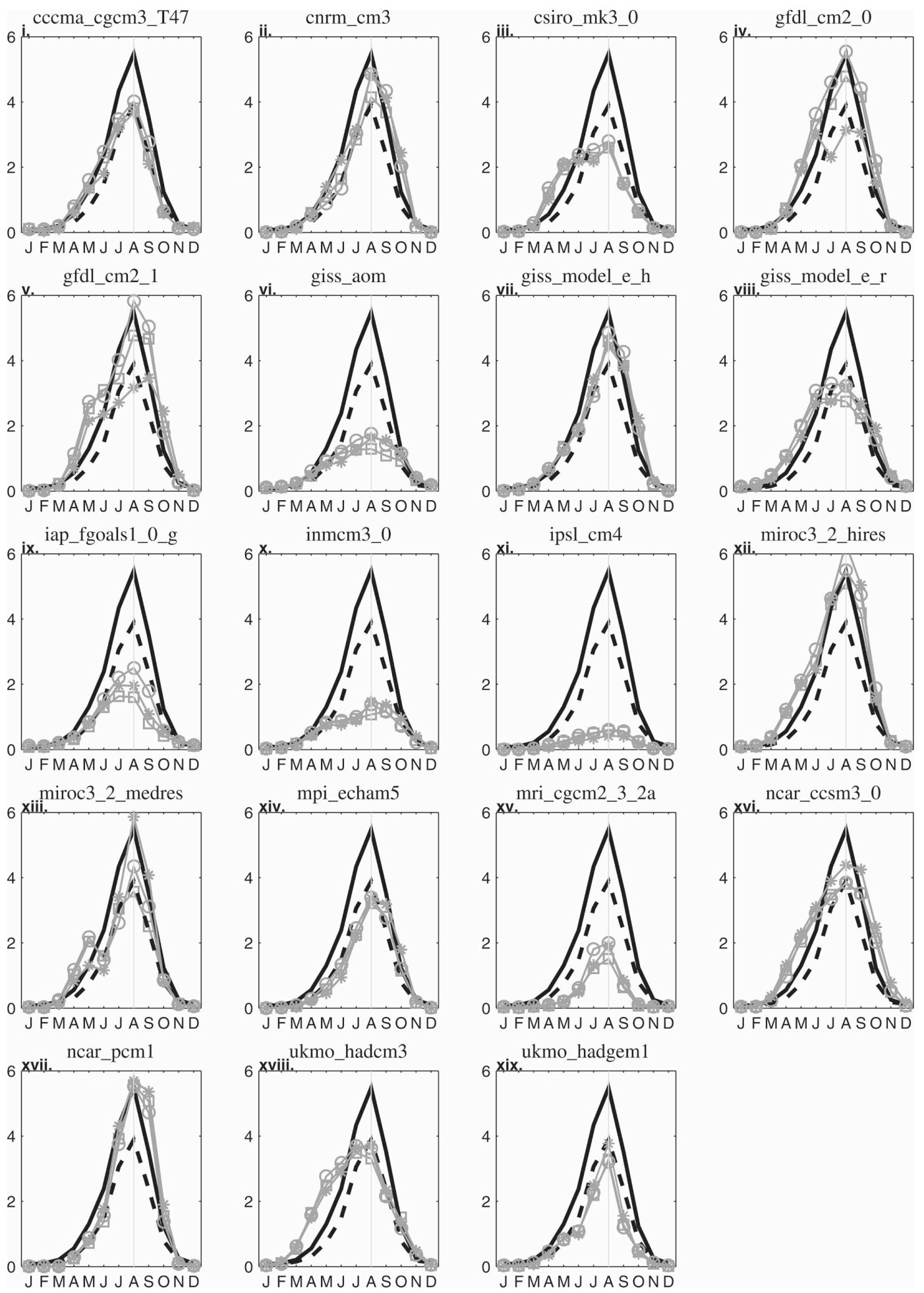

FIG. 2. Annual cycle of Sahel precipitation $\left(\mathrm{mm} \mathrm{day}^{-1}\right)$ in observations (the solid black curve is the mean climatology in the Hulme dataset; the dashed black curve is CMAP) and in simulations by the listed models of the preindustrial epoch (PI, circles), the twentieth century (XX, squares), and the twenty-first century (A1B, asterisks). 

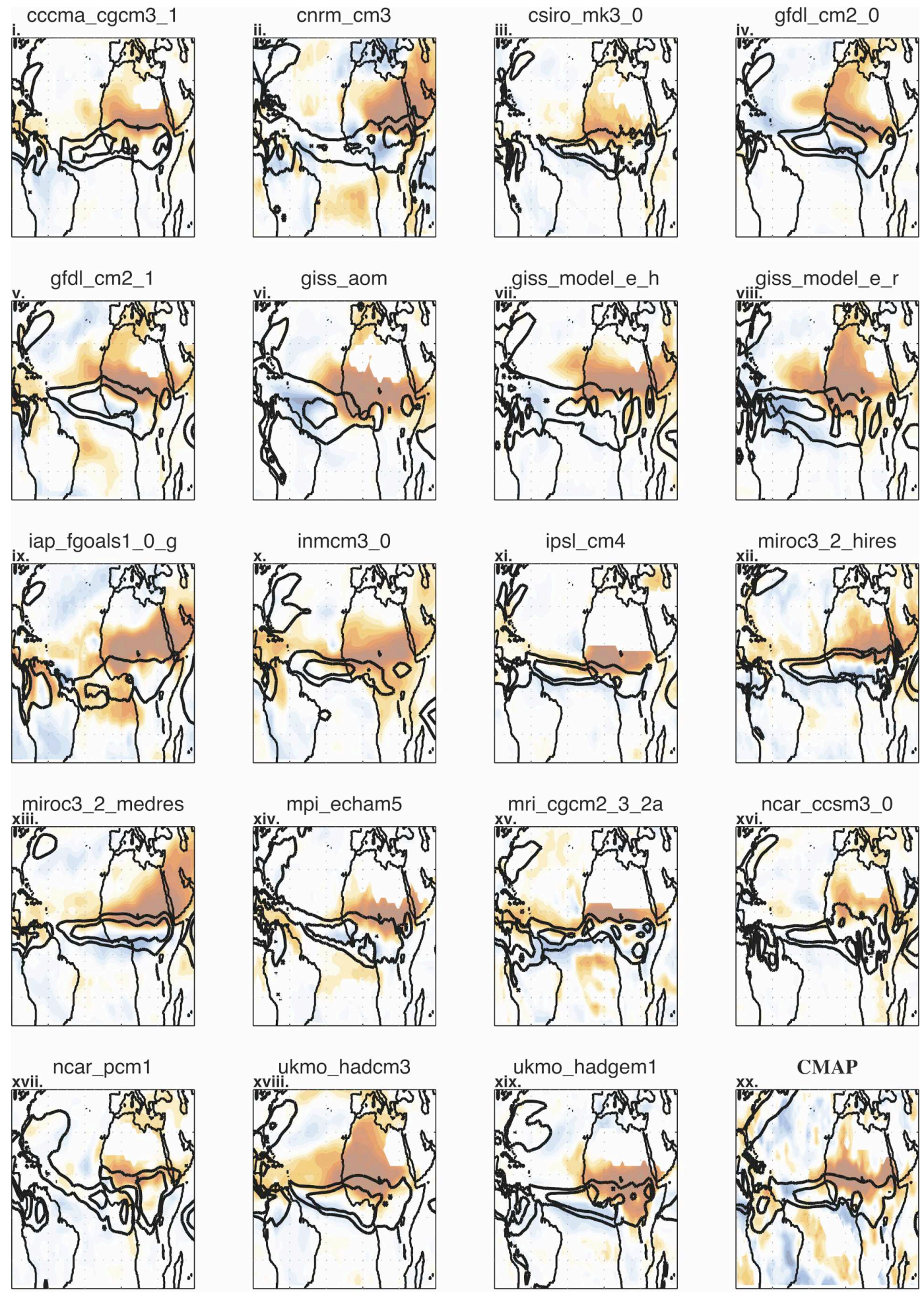



FIG. 3. Contours represent the climatological JAS precipitation in the various models and observations (CMAP), contours of 4 and $8 \mathrm{~mm} \mathrm{day}^{-1}$. Shading represents the correlation between the Sahel index and JAS rainfall. Warm (cold) colors indicate positive (negative) correlations; the shading interval is 0.08 . 

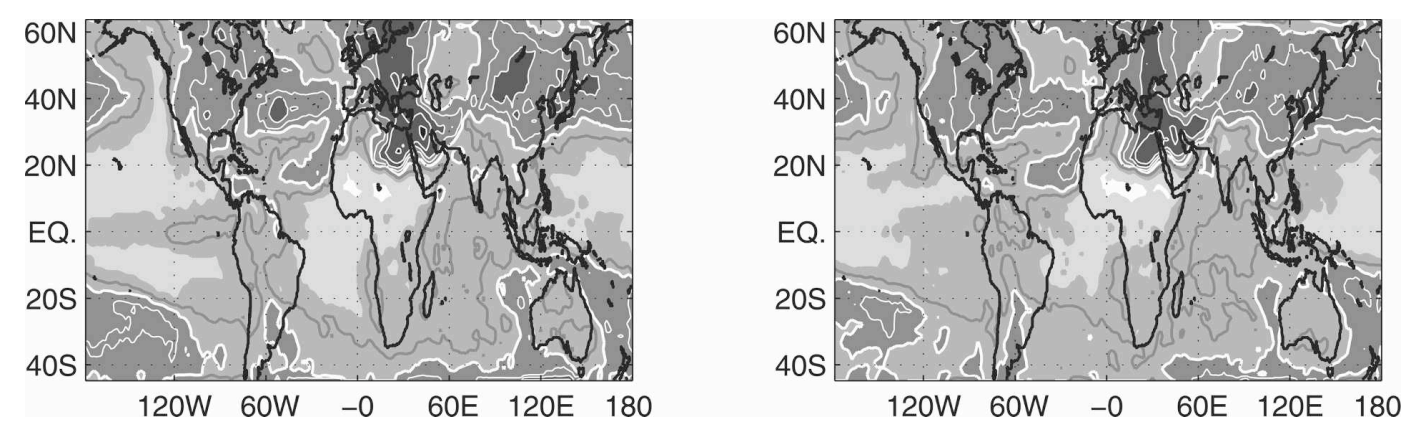

FIG. 4. Percentage of models showing positive (shading in dark grays; white contours) or negative (shading in light grays; black contours) significant correlations between the Sahel index and surface temperature at each grid point. (left) PI and (right) XX detrended simulations. The contour interval is $20 \%$, the shading interval $40 \%$. See text for further details.

with rainfall at the northern edge of the ITCZ, although it is limited to a region near the coast. Overall, this Sahel index, which is based on observations, does capture the local rainfall variability in the coupled models, but the correlation patterns of Fig. 3 are affected by the biases in the models' rainfall climatology. In some models the pattern is too narrow (e.g., Fig. 3xv), in others too wide (e.g., Figs. 3viii and 3xviii), in others not zonal enough (e.g., Fig. 3ii), and in others weak enough to suggest little coherence across the Sahel (e.g., Figs. 3iii and 3xvi). The correlations between the Sahel and oceanic precipitation also vary widely across models, with some models emphasizing the connection to the northern edge of the ITCZ (e.g., Fig. 3xviii) and other emphasizing the dipole with Guinea (e.g., Fig. $3 x i i i)$. In the remainder of this paper we will present results for the Sahel index as defined above, with the understanding that a few of the models do not accurately capture either its mean magnitude or the associated spatial pattern of interannual variability. Two examples of the behavior of the simulated Sahel rainfall index in the XX and A1B integrations are given in Fig. 1.

\section{Relationship between SST and Sahel rainfall in the PI and $X X$ integrations}

As many studies with atmospheric GCMs and prescribed SST have demonstrated, the Sahel droughts and pluvials recorded in the observational record were largely forced by SST. Thus, we begin this section investigating how the models reproduce the statistical relationship between Sahel rainfall and global SST. In this section, we focus on the characteristics of the natural variability and the twentieth-century trend.

Figure 4a displays a measure of the cross-model agreement in reproducing the linear correlation between the summer Sahel rainfall index and global surface air temperature at interannual-to-interdecadal time scales during preindustrial times (for ocean regions, surface air temperature and SST are so tightly linked that we will use the two terms interchangeably). The figure is constructed in the following way: first, we calculate the correlation between the detrended Sahel rainfall and surface temperature time series for each of the 19 PI integrations (detrending should not be necessary, but some of the PI integrations experience climate drift); second, at every grid point we assign a value of +1 if the correlation is significant at the $95 \%$ level and positive, and -1 if it is significant and negative (significance is calculated assuming that each year is an independent sample); and third, we take the sum over all 19 models, and plot it as a percentage.

There is a strong agreement across models on the fact that increased precipitation over the Sahel coexists with a locally cooler surface temperature, most likely because rain leads to cooling through increased surface evaporation and the associated cloudiness leads to a reduction of shortwave input. The positive Sahel correlation with surface temperature in the eastern Sahara and northern Arabian Peninsula is also very robust. Conversely, the relationship between Sahel rainfall and global SST is weaker, according to this metric. For example, there is only a $50 \%$ agreement that the Sahel index is significantly negatively correlated with SST in the tropical Pacific, and the agreement drops further in the eastern equatorial Pacific, where the ENSO signal, even in summer, should be strongest. When we repeat this calculation on a 5-yr running mean, the agreement in the ENSO region becomes greater, suggesting some sensitivity to the details of the SST pattern (see also the discussion of Fig. 6 below). The agreement on the anticorrelation with the south tropical Atlantic exceeds 


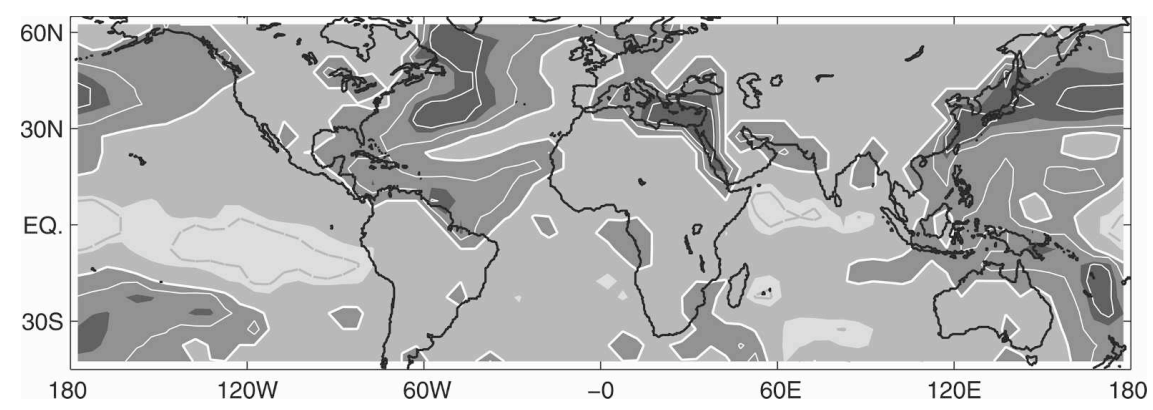

FIG. 5. Same as Fig. 4, but for observed correlations between the Sahel index (Hulme dataset) and SST (Kaplan dataset).

$60 \%$; the correlation pattern in the north tropical Atlantic is weaker and somewhat noisy.

What emerges in Fig. 4a is an overall intermodel agreement on the large-scale pattern of correlation: the models indicate that at interannual-to-interdecadal time scales, a wet (dry) Sahel tends to be associated with cooler (warmer) tropics and a positive (negative) SST gradient across the tropical Atlantic. This pattern is quite similar to that seen in observations (Fig. 5; Folland et al. 1986; Giannini et al. 2005), although the features of the SST pattern that have been deemed more relevant to explain the twentieth-century variability in observations are not necessarily the most robust across the models. In particular, Giannini et al. (2005) stress the importance of the Indian Ocean warming in forcing drought over the Sahel during the later part of the twentieth century, but the PI runs do not reproduce high correlation in this region. A possible explanation is that the relationship between the Indian Ocean and the Sahel is most apparent at the time scale of the forced trend, and is muted when natural variability at shorter time scales is considered. We note that the positive correlation of Sahel rainfall with midlatitude surface temperature is significant in the models but not in observations (Giannini et al. 2005), maybe because of the smaller signal-to-noise ratio of variability in the midlatitudes as compared to the tropics.

The relationship with SST that characterizes the interannual-to-interdecadal variability in Sahel rainfall is robust across different epochs, according to the CMIP3 model. Figure $4 \mathrm{~b}$ (built as Fig. 4a and showing the across-model agreement over significant correlation) shows that the pattern of correlation between the detrended time series of SST and Sahel rainfall in the XX simulations is very similar to that in the PI case. The same result also holds for the A1B global warming integrations (see Fig. 9 in the next section). We conclude that the interannual-to-interdecadal relationship be- tween Sahel rainfall and global surface temperature patterns is left unchanged in its broader features as the basic state changes under the effect of anthropogenic forcings.

To focus on the large-scale pattern that has emerged in Fig. 4 (instead of looking at gridpoint-by-gridpoint agreement) and to consider each model individually, we now assess the relationship between Sahel rainfall and two indices of large-scale SST variability. We choose the SST indices based on Fig. 4 and the body of literature regarding the relationship between Sahel rainfall and SST. First of all, we limit our indices to the tropical SST, which is the main driver of tropical rainfall changes. One index is the mean Indo-Pacific SST; this broad-scale index emphasizes time scales longer than the interannual ENSO time scale and also captures the variability of the Indian Ocean that has been implicated in the long-term drought of the Sahel in the twentieth century [see, e.g., Giannini et al. (2003) for the influence of ENSO and Indian Ocean SST on Sahel rainfall at different time scales]. The second index is the north-south SST gradient in the tropical Atlantic. The studies that viewed the Sahel drought as part of a shift in the meridional position of the ITCZ have emphasized the role of either the local, Atlantic SST (e.g., Cook and Vizy 2006) or a global, interhemispheric gradient (e.g., Folland et al. 1986); we choose to focus on the local SST gradient because we do not see in Fig. 4 any evidence of interhemispheric antisymmetry in the pattern of correlation to SST. On the contrary, we see a high degree of symmetry in the two hemispheres, with negative correlation in the tropics and positive correlation poleward, only weakly disrupted in the north tropical Atlantic by a patch of positive correlations below $20^{\circ} \mathrm{N}$ and along the African coast.

Other choices of indices were also possible. We have repeated our analysis using three SST indices (the tropical Atlantic, the Atlantic meridional gradient, and either the Indo-Pacific or the Pacific) to better capture 

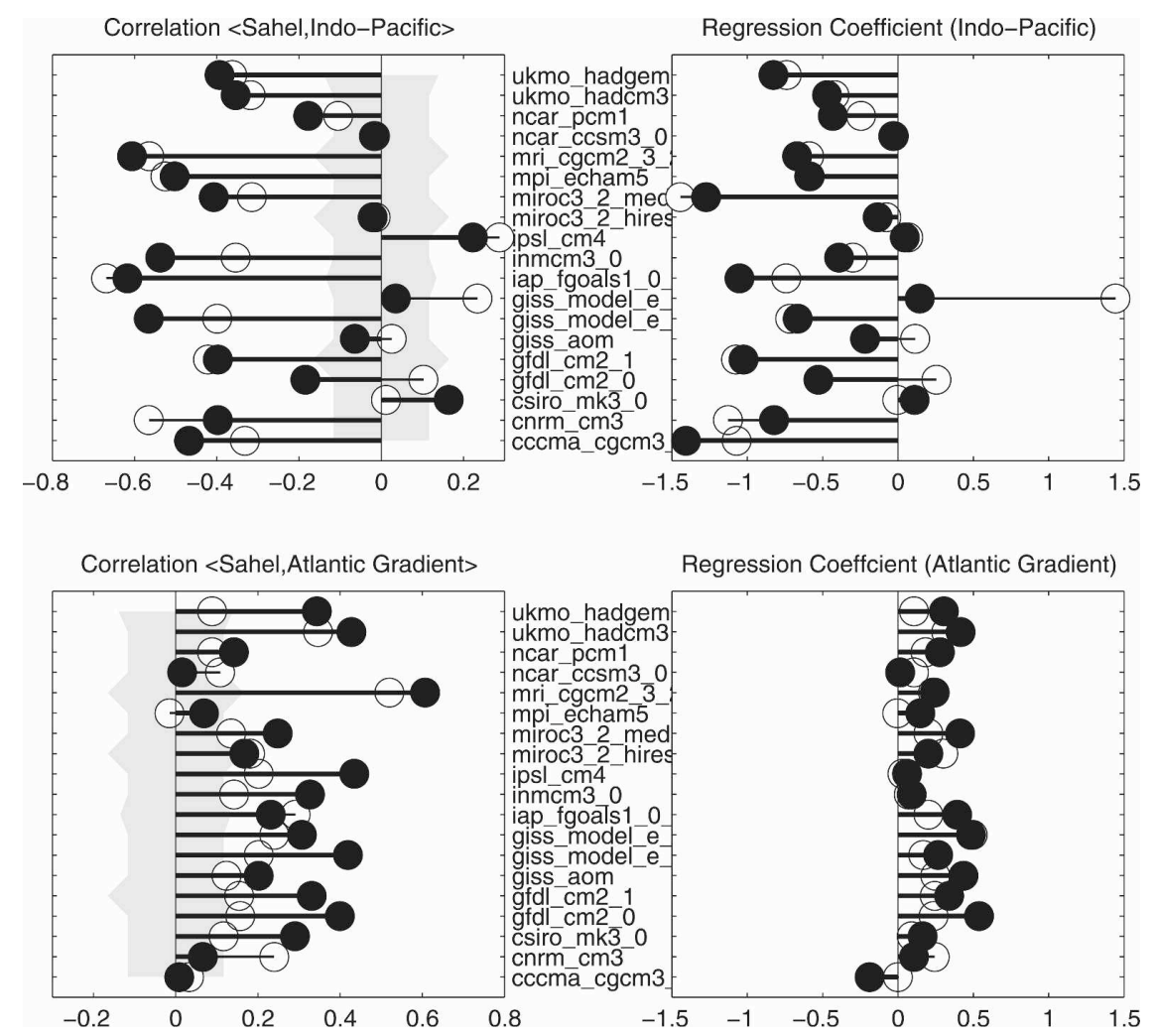

FIG. 6. (left) Preindustrial correlations and (right) regression coefficients between the Sahel index and (top) the area-averaged Indo-Pacific SST and (bottom) the difference of north tropical Atlantic and south tropical Atlantic SSTs. Open circles indicate time series that have been detrended; filled circles indicate detrended and 5-yr running mean time series.

both the meridional and the zonal gradients of tropical SST and have found no significant differences in our results.

To focus on the Sahel-SST relationship that emerges from natural variability, we analyze the PI integrations. We calculate the box average SST in the tropical IndoPacific $\left(20^{\circ} \mathrm{S}-20^{\circ} \mathrm{N}, 50^{\circ} \mathrm{E}-90^{\circ} \mathrm{W}\right)$ and a bulk tropical Atlantic SST meridional gradient [north $\left(7^{\circ} \mathrm{N}-30^{\circ} \mathrm{N}, 70^{\circ}-\right.$ $\left.20^{\circ} \mathrm{W}\right)$ minus south $\left.\left(20^{\circ} \mathrm{S}-7^{\circ} \mathrm{N}, 40^{\circ} \mathrm{W}-5^{\circ} \mathrm{E}\right)\right]$ and calculate the correlation of these coarser indicators of patterns of SST anomalies with the Sahel index. Figure 6 shows that there is a much stronger model agreement according to this metric than in the case of gridpointby-gridpoint comparison. Correlations are more consistent and stronger when we filter out the fastest interannual variability with a 5 -yr running mean, so we discuss this case. Out of 19 models, 13 have a significant (at the 95\% level, shown in Fig. 6 by the gray shading) negative correlation between the Sahel index and IndoPacific SST (2 models show significant positive correlations), and 15 models show significant positive correlations with the Atlantic north-south gradient (the rest of the models show insignificant, but still positive, correlations). ${ }^{2}$

The right panels of Fig. 6 show the regression coefficients for a bivariate linear model that uses the IndoPacific SST and the Atlantic SST meridional gradient indices to predict variations in Sahel rainfall. According to this measure, although the relationship between the Sahel and the Atlantic is more robust, the relationship with the Indo-Pacific is more influential: the regression coefficients for the Indo-Pacific are about twice as large as those for the Atlantic.

A rough estimate of how much (5-yr running mean) Sahel rainfall variability is forced by SSTs in these coupled integrations can be obtained by comparing the

\footnotetext{
${ }^{2}$ Significance for the 5-yr running means is calculated considering 1 degree of freedom every 5 points. Correlations with single basins are somewhat less robust than with the Indo-Pacific and Atlantic gradient indices: correlations with the Pacific and South Atlantic indices resemble those with the Indo-Pacific and Atlantic gradient, respectively, but correlations with the North Atlantic change sign in different models, confirming the weaker relationship seen in Fig. 4.
} 




FIG. 7. Correlations between the simulated and linearly predicted Sahel index in the (left) PI and (right) XX integrations. The coefficients of the linear model come from the JAS, detrended, 5-yr running mean time series of Sahel rainfall, Indo-Pacific SST, and Atlantic SST gradient in the PI integrations. All time series have been subjected to a 5-yr running mean; dots refer to detrended time series and squares to time series retaining the trend.

prediction of the simple bivariate regression and the coupled models' Sahel rainfall variations.

Figure 7a shows the correlation between the linearly predicted Sahel index and the original simulated Sahel index in the integrations used to train the regression model (i.e., the PI integrations). As expected, all models show positive correlations, and 13 show correlations better than 0.4. The fraction of variance in Sahel rainfall explained by SST is not large, but this is to be expected because we are considering only one realization of a coupled integration, and the variability linked to SST is small compared to the total variability. Another possible explanation is that the regression model, although accurate in reproducing multidecadal variability, tends to dampen the variability at shorter time scales (not shown). The spread among models is large: correlations range between about 0.7 [Meteorological Research Institute (MRI)] to virtually zero [Community Climate System Model, version 3 (CCSM3)], an expected result given the range of Sahel-SST correlations shown in Fig. 6.

Can we use the Sahel-SST relationship that we have derived from the natural variability in the PI integrations to interpret the behavior of Sahel rainfall in the presence of external forcings during the twentieth and twenty-first centuries? Here, we address these questions for the XX integrations; the case of the twentyfirst century is explored in the next section.

Figure $7 \mathrm{~b}$ shows the correlation between the $\mathrm{XX}$ simulated Sahel and the predicted Sahel (obtained from the XX SST indices, using the regression coefficients derived from the PI integrations) calculated either for the 5-yr running mean and the detrended time series, or the 5-yr running mean time series [for which only the shortest time scales have been muted, and variance arises at all longer time scales, including the centennial trend, which is largely externally forced (denoted by squares in Fig. 7b)]. Only one realization of the XX simulations is used for each model. Our simple linear model-derived from the natural variability in preindustrial times-has some predictive skill for the twentieth century whether we predict the full time series or only its shorter-term variability. Correlations between the original and the synthetic Sahel time series are positive in most cases [with the notable exception of the two National Center for Atmospheric Research (NCAR) and the Max Planck Institute (MPI) models] whether or not the centennial trend is included. This would seem to indicate that the trend in twentieth-century Sahel rainfall arises from the SST trends through the same mechanisms that shape the SST-forced interannual variability. The correlation between the predicted and simulated Sahel rainfall is in general somewhat better when we predict the full time series than when we predict only its short-term variability, which is consistent with the expectation that variability at shorter time scales would be affected by atmospheric internal variability more than would the trend.

A direct comparison (Fig. 8) of the simulated Sahel twentieth-century trends with those linearly predicted from the XX SST confirms that the linear model captures the sign and order of magnitude of the simulated trends. In 11 out of 19 models the linear model produces a stronger drying trend than simulated; this could be just by chance, but the fact that the spurious increases of the negative trend are so much larger than any spurious decrease is suggestive of a tendency for the regression model to overestimate the drying trend. This behavior, and the behavior over the twenty-first century described in the next section, might indicate 


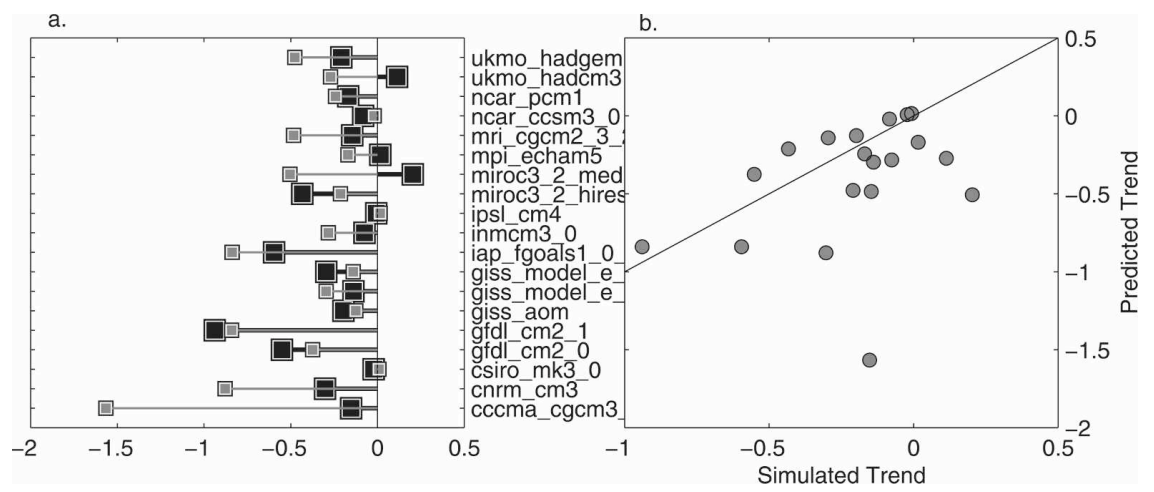

FIG. 8. (a) Linear trends in the simulated XX Sahel rainfall (large squares) and the predicted Sahel time series obtained by linear regression from the simulated XX SST (small squares). The linear regression model was trained on the detrended, 5-yr running means of the PI simulations. The trends are calculated over the length of the entire XX simulations, which might cover different periods for different models. (b) Scatterplot of the simulated and predicted trends shown in (a).

that there are other influences on Sahel rainfall, distinct from SST and induced directly by the external forcings.

As another test of the robustness of the SST-Sahel rainfall relationship, we perform a similar calculation, using the first half of the XX integrations to build a linear model for Sahel rainfall and validating the model by predicting Sahel rainfall changes in the second half of the integrations. In this case, we retain the trend in all time series so the forced component of the relationship can be captured by the linear model (to the extent that the forced signal is present in the early part of the twentieth century and is not overwhelmed by natural variability at shorter time scales). The linear model shows some skill in a majority of models (not shown) but is not as accurate as the model derived from the preindustrial natural variability, and it produces negative correlations between the predicted and simulated Sahel rainfall time series in four of the models during the validation period.

\section{Relationship between SST and Sahel rainfall in the A1B integrations}

The relationship with global SST that characterizes the natural variability of the Sahel is robust across epochs: the large-scale pattern of correlation between the Sahel index and surface temperature that emerges from the A1B integrations at interannual-to-interdecadal time scales-when the trend is removed from the Sahel and temperature time series-is indistinguishable from that of the preindustrial and twentieth-century simulations (cf. Fig. 9 to Fig. 4 in the previous section). When the trend is retained in the time series, the models disagree in the relationship between Sahel rainfall and global trends in surface temperature. In a majority of models, the surface global warming is accompanied by a positive trend in Sahel rainfall; in some models the warming is accompanied by drying, and in others there is no significant correlation.

Figure 10 shows how, in each A1B simulation, the Sahel-SST relationship changes when the centennial trend is kept or removed. Specifically, Fig. 10 shows the correlation between the simulated and predicted twenty-first-century Sahel for two linear regression models: the first is the one introduced in the previous section in Figs. 6 and 7; the second is similar but is built on the entire XX runs (5-yr running means are applied and the trend is retained). In both cases-whether the bivariate regression model is built on the natural variability in the preindustrial runs (Fig. 10, left-hand side) or on the forced twentieth-century runs (Fig. 10, righthand side) - variations in SST capture only the interannual-to-interdecadal variations in Sahel rainfall (i.e.,

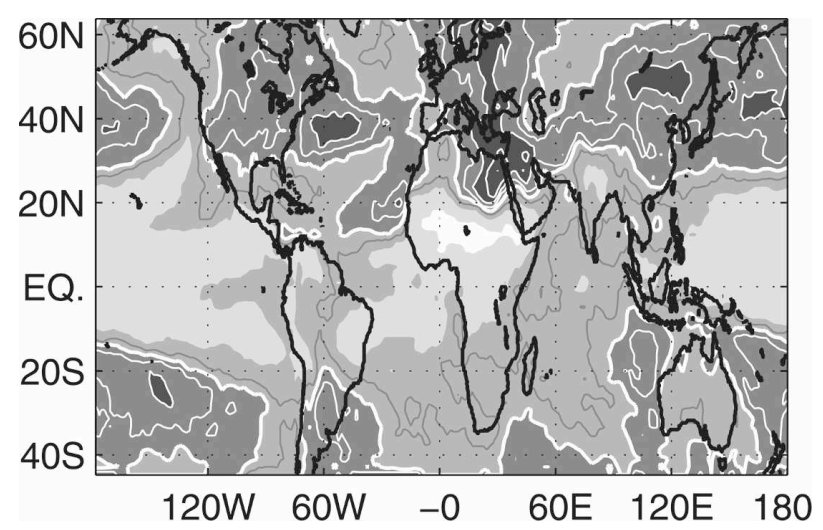

FIG. 9. Same as Fig. 4, but for the A1B simulations. 


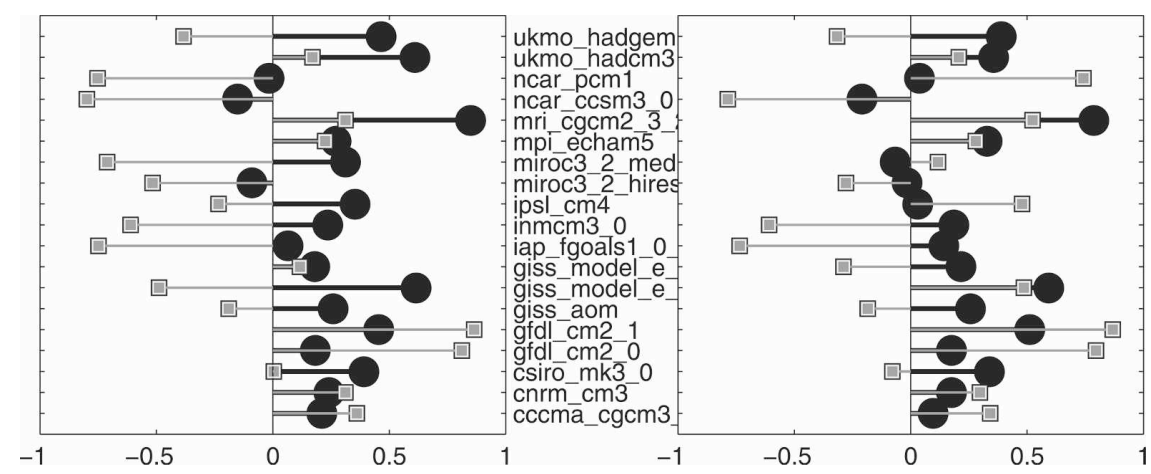

FIG. 10. Correlations between the simulated and linearly predicted Sahel index in the A1B integrations. The coefficients of the linear model come from the JAS, 5-yr running mean time series of Sahel rainfall, Indo-Pacific SST, and Atlantic SST gradient in the (left) detrended PI and (right) XX integrations. All A1B time series have been subjected to a 5-yr running mean; dots refer to A1B detrended time series and squares to A1B time series retaining the trend.

variations in the detrended time series, shown as circles) and not the trend: in a majority of models the correlation between the simulated Sahel and the synthetic, SST-derived Sahel is negative when the trend is retained in the calculations (squares). To test whether the two predictors used for interannual variability were insufficient to capture the important pattern of SST anomalies in the forced twenty-first-century case, we also built a linear model using the tropical Atlantic SST (or, which is the same, using the north and south tropical Atlantic as independent predictors) in addition to the Indo-Pacific and Atlantic gradients. This way we can better capture the variability of the zonal gradient of tropical SST. Nonetheless, the A1B Sahel rainfall could not be captured in many of the models, regardless of whether the model was built from the PI or the XX integrations.

If we wanted to ascribe the disparate projections for twenty-first-century Sahel rainfall to SST, we might consider a few possibilities. One is that the pathways of SST influence are the same across models and epochs, but different models produce different SST anomalies under global warming. Another possibility is that although the SST anomalies are the same across models, each model weighs the influence of different ocean basins differently, so a drying influence is dominant in one model, but not in others. A third possibility is that the linear response to SST change, which was dominant in driving natural and forced anomalies in Sahel rainfall in the twentieth century, is not relevant anymore, with new influences arising either from nonlinearities or from new patterns of SST anomalies. Finally, ascribing the disparate projections for twenty-first-century Sahel rainfall to SST might not be possible: SST might cease to be the most important driver for Sahel rainfall change in all the models, and new influences from some other factor in the climate system might become dominant.

The linear regression model presented in Fig. 10 accounts for the first two possibilities: it takes into account both differences in trends and in the sensitivities. Thus, to the extent that linear thinking and our choice of SST indices are warranted, we already know that model discrepancies cannot be explained by SST.

To explore this point further, we show (Fig. 11) the trend in Sahel rainfall, mean tropical Indo-Pacific SST, tropical Atlantic meridional SST gradient, and three more indices that describe in more detail the pattern of SST or atmospheric circulation changes in the Pacific: the difference in sea level pressure between grid points at Tahiti and Darwin, the difference in SST between the west and east Pacific, and the difference between the equatorial and subtropical SST in the Pacific. We have included these indices because they provide some insight into whether a model produces an El Niño- or La Niña-like climate change pattern (in the first two cases) or simulates an enhanced equatorial response in the Pacific [a pattern that might better describe the structure of the global warming signal, according to Liu et al. (2005)]. These indices capture details in the IndoPacific anomalies not captured by the mean SST and might indicate changes in the circulation relevant for the Sahel. In all panels in Fig. 11, the gray shading indicates the sign of the Sahel trend in each simulation.

As expected, the warming in the Indo-Pacific is a feature of all model simulations, and thus bears no direct relation to discrepancies in the sign of Sahel rainfall anomalies. Changes in the Atlantic gradient, instead, are much more model dependent, with different models producing anomalies of different signs, but there is no correspondence between the anomalies in the Atlantic gradient and those in Sahel rainfall. For 

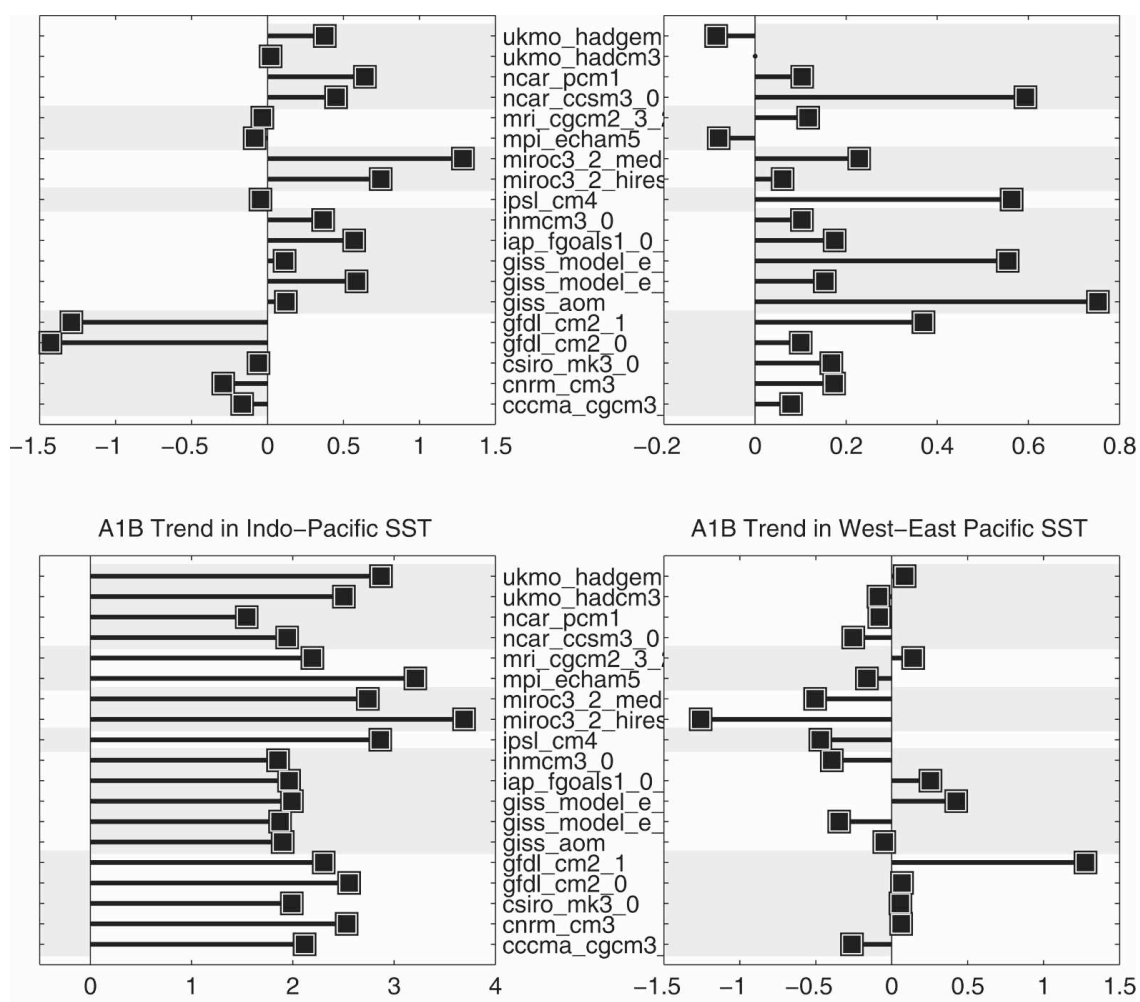

A1B Trend in Atlantic Dipole



A1B Trend in Enhanced Equatorial Response

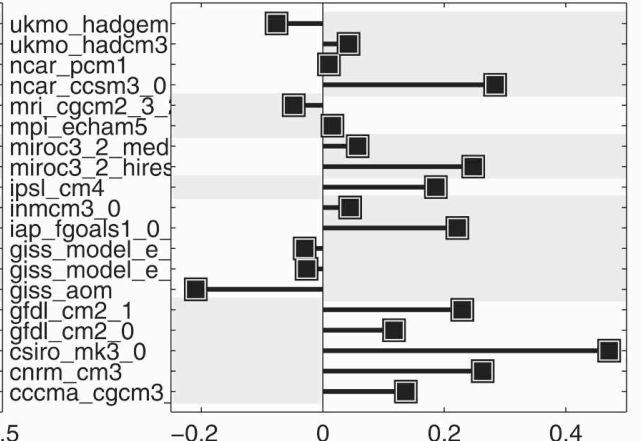

FIG. 11. Linear trends over the years 2000-2100 in the A1B integrations in the (top left) Sahel index, (middle left) Indo-Pacific SST, (bottom left) Atlantic SST meridional gradient, (top right) Tahiti-Darwin sea level pressure difference, (middle right) west equatorial Pacificeast equatorial Pacific SST difference, and (bottom right) the enhanced equatorial response index (Liu et al. 2005).

example, the two Model for Interdisciplinary Research on Climate (MIROC) models have differently signed anomalies in the gradient, but both produce strong positive anomalies in Sahel rainfall. Conversely, the two GFDL models dry the Sahel, but not (as already reported by Held et al. 2005) because of a negative trend in the Atlantic gradient. Discrepancies in the sign of the trend for the Pacific indices also fail to match those in the Sahel rainfall trend, suggesting that even more refined indices of SST variations would fail to explain the twenty-first-century changes in the Sahel in a consistent way across all models (this has been tested in regression models).

Finally, we present evidence that the sensitivity of Sahel rainfall to SST changes more consistently from one epoch to the next than from one model to another: Fig. 12 shows the coefficients of three bivariate linear regression models for Sahel rainfall that use the IndoPacific and Atlantic gradient indices as predictors and are based on the PI, XX, and $\mathrm{A} 1 \mathrm{~B}$ integrations. 


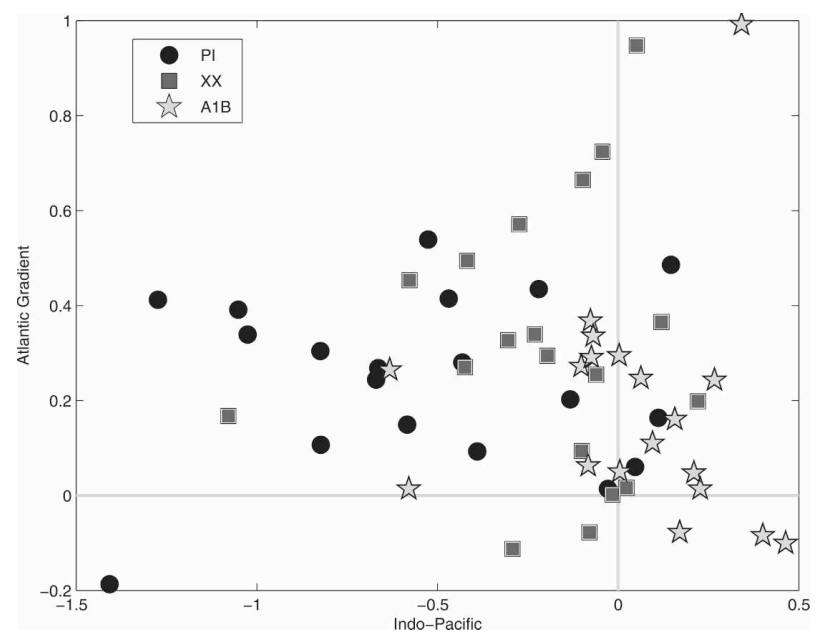

FIG. 12. Scatterplot of the bivariate linear model regression coefficients between the Sahel index and the Indo-Pacific SST and Atlantic SST meridional gradient. Dots indicate the PI integrations, squares indicate $\mathrm{XX}$, and stars indicate A1B.

We see that the relationship between the Sahel and the Atlantic gradient is quite consistent across epochs (and thus persists despite the presence or absence of anthropogenic forcings). The relationship with the Indo-Pacific is stronger for many models, but it is more variable and is sensitive to the presence of the trend both in the twentieth century (the coefficients maintain the same sign as in the PI integrations in most cases, but their magnitude is in general much reduced) and especially in the twenty-first century (the regression coefficients become positive in a majority of models).

This suggests that the negative correlations between the simulated and linearly predicted Sahel in the A1B scenario shown in Fig. 10, like those for the latter part of the XX simulations mentioned in the previous section, are a consequence of a changing relationship between the Sahel and the Indo-Pacific warming that becomes evident going from the preindustrial to the twentieth century and from the twentieth to the twenty-first century.

\section{Conclusions}

The projection for Sahel rainfall changes in response to global warming is highly uncertain, with some coupled models predicting strong dry anomalies, others predicting strong wet anomalies, and most predicting more modest anomalies of both signs. This disagreement is even more puzzling when compared to the agreement of a vast majority of the CMIP3 models in reproducing a dry Sahel in the late twentieth century, compared to the preindustrial epoch.
Given that previous modeling studies have shown that global SST changes have paced the Sahel droughts and pluvials of the recent history, we have explored the statistical relationship between rainfall and global SST as it is simulated by the CMIP3 models in the preindustrial (PI) era, the twentieth century (XX) and the twenty-first century (A1B). The large-scale features of the observed correlation between Sahel rainfall and global SST are reproduced by a majority of models in the context of their natural variability (i.e., when we calculate correlations and regressions between detrended time series). Sahel rainfall is negatively correlated with the tropical Indo-Pacific SST and positively correlated with the tropical Atlantic meridional SST gradient.

We have used the PI integrations to construct a linear, bivariate model that predicts Sahel rainfall variations from changes in Indo-Pacific SST and the Atlantic SST gradient. This model has some skill in predicting interannual-interdecadal variability in Sahel rainfall in both the XX and A1B integrations. When it is used to predict centennial trends, the model is still useful for the simulations of the twentieth century, but fails during the twenty-first century in a majority of models.

From the above analysis, we conclude the following: (i) at interannual time scales, the relationship linking Sahel rainfall to the global SST does not change in any significant or consistent way from the PI, to the $\mathrm{XX}$, to the A1B cases; (ii) the forced component of Sahel rainfall variations during the twentieth century can be explained at least in part by the corresponding variations in the Indo-Pacific SST and the Atlantic SST meridional gradient; and (iii) the centennial trend that characterizes Sahel rainfall changes in the A1B integration is not explained, for a majority of models, by the same linear link to SST that explained rainfall variations during preindustrial times and the twentieth century.

In the global warming scenario, the Indo-Pacific warms and there is little trend in the Atlantic gradient. By the mechanisms operating at interannual-to-interdecadal time scales, the Pacific warming would induce a drought in the Sahel, but most models simulate a wetting of the Sahel, hence the negative correlations between the predicted and simulated Sahel. Indeed, there is a very good correspondence between the models for which our "prediction" model fails and those that simulate a wetting of the Sahel in the twenty-first century.

It appears that the future greenhouse-gas-forced change in Sahel rainfall is controlled by different mechanisms and cannot be captured by the simple linear relationship that has characterized the past. It may be that the pattern of forced SST anomalies simulated for the twenty-first century is different enough from the 
patterns seen at interannual time scales and in the forced response during the twentieth century that different pathways of SST influence become dominant. It is possible that small-scale features of the tropical SST anomalies not captured in our analysis (which is based on coarse indices) are essential to determining Sahel rainfall changes. Other possibilities are that extratropical SSTs play an important role or that the assumption of linearity fails.

Alternatively, it may be that SST is not the only player in a warmer world. The finding that a model based on SST variations both overestimates the Sahel drying trend of the twentieth century and cannot account for the twenty-first-century moistening of the Sahel predicted by most models is consistent with the following hypothesis: in most models, atmospheric greenhouse gases exert a substantial direct positive effect on Sahel rainfall, unmediated by SST. Further testing is needed to confirm this interpretation of our results.

Another important conclusion that arises from this analysis is that a faithful reproduction of the twentieth century is not in itself assurance that any given model will be accurate in its prediction of the future. More specifically, the fact that two models both dry the Sahel in the twentieth century and do so through the same influence of SST anomalies does not mean that they will behave similarly in a simulation of the future. Therefore, similarity to observations in a simulation of the twentieth-century climate appears to be a necessary but insufficient condition for a trustworthy prediction of the future.

Acknowledgments. We thank Dr. Jian Lu for many discussions and ideas, the international modeling groups that have produced the datasets here analyzed, and the Program for Climate Model Diagnosis and Intercomparison (PCMDI) for serving the CMIP3 data from their Web site. The authors acknowledge support from the Earth Institute Cross-Cutting Initiative on Climate-Society Interactions at Columbia University, the David and Lucile Packard Foundation Fellowship in Science and Engineering, and NOAA (Grants NA07GP0213 and NA06OAR4310143).

\section{REFERENCES}

Bader, J., and M. Latif, 2003: The impact of decadal-scale Indian Ocean sea surface temperature anomalies on Sahelian rainfall and the North Atlantic Oscillation. Geophys. Res. Lett., 30, 2169, doi:10.1029/2003GL018426.

Biasutti, M., and A. Giannini, 2006: Robust Sahel drying in response to late 20th century forcings. Geophys. Res. Lett., 33, L11706, doi:10.1029/2006GL026067.
Cook, K., and E. K. Vizy, 2006: Coupled model simulations of the West African monsoon system: Twentieth- and twenty-firstcentury simulations. J. Climate, 19, 3681-3703.

Davey, M., and Coauthors, 2002: STOIC: A study of coupled model climatology and variability in tropical ocean regions. Climate Dyn., 18, 403-420.

Folland, C. K., T. N. Palmer, and D. Parker, 1986: Sahel rainfall and worldwide sea temperature, 1901-85. Nature, 320, 602687.

Giannini, A., R. Saravanan, and P. Chang, 2003: Oceanic forcing of Sahel rainfall on interannual to interdecadal time scales. Science, 302, 1027-1030.

,-- , and -2005 : Dynamics of the boreal summer African monsoon in the NSIPP1 atmospheric model. Climate Dyn., 25, 517-535.

Gore, A., 2006: An Inconvenient Truth. Rodale Press, 325 pp.

Haarsma, R. J., F. M. Selten, S. L. Weber, and M. Kliphuis, 2005: Sahel rainfall variability and response to greenhouse warming. Geophys. Res. Lett., 32, L17702, doi:10.1029/2005GL023232.

Held, I. M., T. L. Delworth, J. Lu, K. L. Findell, and T. R. Knutson, 2005: Simulation of Sahel drought in the 20th and twenty-first centuries. Proc. Natl. Acad. Sci. USA, 102 (50), 17 891-17 896.

Hoerling, M., J. Hurrell, J. Eischeid, and A. Phillips, 2006: Detection and attribution of twentieth-century northern and southern African rainfall change. J. Climate, 19, 3989-4008.

Houghton, J., L. Meira Filho, B. Callander, N. Harris, A. Kattenberg, and K. Maskell, Eds., 1996: Climate Change 1995: The Science of Climate Change. Cambridge University Press, 572 pp.

Hulme, M., 1992: A 1951-80 global land precipitation climatology for the evaluation of general circulation models. Climate Dyn., 7, 57-72.

Knutson, T. R., D. L. Delworth, K. W. Dixon, and R. J. Stouffer, 1999: Model assessment of regional surface temperature trends (1949-1997). J. Geophys. Res., 104, 30 981-30 996.

Lau, K. M., S. S. P. Shen, K.-M. Kim, and H. Wang, 2006: A multimodel study of the twentieth-century simulations of Sahel drought from the 1970s to 1990s. J. Geophys. Res., 111, D07111, doi:10.1029/2005JD006281.

Liu, Z., S. Vavrus, F. He, N. Wen, and Y. Zhong, 2005: Rethinking tropical ocean response to global warming: The enhanced equatorial warming. J. Climate, 18, 4684-4700.

Lu, J., and T. Delworth, 2005: Oceanic forcing of the late 20th century Sahel drought. Geophys. Res. Lett., 32, L22706, doi:10.1029/2005GL023316.

Neelin, J. D., C. Chou, and H. Su, 2003: Tropical drought regions in global warming and El Niño teleconnections. Geophys. Res. Lett., 30, 2275, doi:10.1029/2003GL018625.

Nicholson, S. E., 1980: The nature of rainfall fluctuations in subtropical West Africa. Mon. Wea. Rev., 108, 473-487.

- B. Some, and B. Kone, 2000: An analysis of recent rainfall conditions in West Africa, including the rainy seasons of the 1997 El Niño and the 1998 La Niña years. J. Climate, 13, 2628-2640.

Rosenfeld, D., Y. Rudich, and R. Lahav, 2001: Desert dust suppressing precipitation: A possible desertification feedback loop. Proc. Natl. Acad. Sci. USA, 98, 5975-5980.

Rotstayn, L. D., and U. Lohmann, 2002: Tropical rainfall trends and the indirect aerosol effect. J. Climate, 15, 2103-2116.

Stott, P. A., S. F. B. Tett, G. S. Jones, M. R. Allen, J. F. B. Mitch- 
ell, and G. J. Jenkins, 2000: External control of 20th century temperature by natural and anthropogenic forcings. Science, 290, 2133-2136.

Sutton, R. T., B. Dong, and J. M. Gregory, 2007: Land/sea warming ratio in response to climate change: IPCC AR4 model results and comparison with observations. Geophys. Res. Lett., 34, L02701, doi:10.1029/2006GL028164.

Tippett, M., and A. Giannini, 2006: Potentially predictable components of African summer rainfall in an SST-forced GCM simulation. J. Climate, 19, 3133-3144.
Xie, P., and P. A. Arkin, 1996: Analyses of global monthly precipitation using gauge observations, satellite estimates, and numerical model predictions. J. Climate, 9, 840-858.

— , and — 1997: Global precipitation: A 17-year monthly analysis based on gauge observations, satellite estimates, and numerical model outputs. Bull. Amer. Meteor. Soc., 78, 25392558.

Zeng, N., J. D. Neelin, K.-M. Lau, and C. J. Tucker, 1999: Enhancement of interdecadal climate variability in the Sahel by vegetation interaction. Science, 286, 1537-1540. 